\title{
Duration of Diabates Mellitus and Mild Cognitive Impairment among People with Type 2 Diabetes Mellitus in Semarang City, Indonesia
}

\author{
Lukman Fauzi ${ }^{1}$, Lindra Anggorowati ${ }^{2}$, Almira Dianti $^{3}$ \\ \{lukman.ikm@mail.unnes.ac.id ${ }^{1}$, lindranggorowati@gmail.com², almiradianti@gmail.com ${ }^{3\}}$ \\ Universitas Negeri Semarang, Indonesia ${ }^{1}$ \\ Universitas IVET, Indonesia ${ }^{2}$ \\ Brangsong Primary Healthcare Center, Indonesia ${ }^{3}$
}

\begin{abstract}
The prevalence of type 2 Diabetes Mellitus (T2DM) at Gunungpati Primary Healthcare Center (PHC) in 2017-2019 were 1,323, 1,168, and 864 per 100,000 population. Complications of DM are mild cognitive impairment (MCI), leg ulcers, and death. The prevalence of MCI among people with T2DM at Gunungpati PHC was 70\% (54\%-86\%). We investigated the association of duration of T2DM and other risk factors with MCI. It was a case-control study. The sample was 68 cases and 68 controls. Variables were assessed with structured questionnaires and MMSE. Data were analyzed with logistic regression. Of the total 136 subjects, there were 61 subjects $(44.85 \%)$ with duration of $\mathrm{T} 2 \mathrm{DM} \geq 5$ years and 75 subjects $(55.14 \%)$ with duration of $\mathrm{T} 2 \mathrm{DM}<5$ years. After adjusted for other variables, risk factors associated with MCI were duration of T2DM (OR: 3.24 ; 95\%CI: $1.42-7.42)$, age (OR: 6.67; 95\%CI: 2.15-20.73), physical activity (OR: 3.65 ; 95\%CI: 1.61-8.26), and stress (OR: 4.37; 95\%CI: 1.36-14.06).
\end{abstract}

Keywords: Duration, T2DM, MCI

\section{Introduction}

Non-Communicable Diseases (NCD) cause more deaths than other causes, and it is projected that this number will continue to increase from 38 million deaths in 2012 to 52 million deaths in 2030 [1]. Seventy percent of the total deaths in the world and more than half the burden of the disease is Diabetes Mellitus (DM) [1]. Based on data from the Basic Health Research, the prevalence of people with DM aged 15 years and over increased from $6.9 \%$ in 2013 to $8.5 \%$ in 2018 [2]. In Central Java, the prevalence of DM was $20.6 \%$ after hypertension at $57.1 \%$ in 2018 [3]. While in Semarang City, DM cases increased signficantly after hypertension with the most cases in the age group of 45-65 years. In Gunungpati Primary Healthcare Center (PHC), the prevalence of Type 2 DM (T2DM) during 2017-2019 was 1,323, 1,168, and 864 per 100,000 population, respectively.

Some common complications of T2DM are Mild Cognitive Impairment (MCI), angina, dialysis, foot ulcers, proteinuria, amputations, peripheral arterial disease (PDA), heart disease and stroke, neuropathy (nerve damage), diabetic retinopathy, kidney failure, and death [4]. MCI is a condition of objective cognitive impairment based on neuropsychological tests with clinical symptoms leading to the occurrence of dementia [5]. The diagnosis of MCI is based on amnestic 
dysfunction, including learning, memory, perceptual, and central functions of executive impairment. Study showed that MCI is referred to as a clinical condition between aging and Alzheimer's disease in which a person experiences memory loss to a greater extent with age, but there are no clinical symptoms of Alzheimer's disease [6]-[10]

MCI is the prodromal stage of Alzheimer's disease which is influenced by gender differences. According to previous studies, T2DM is a risk of MCI that can develop into Alzheimer's due to vascular dysfunction, oxidative stress, and inflammation. Epidemiological studies show that T2DM is a risk factor for cognitive impairment, dementia, and Alzheimer's disease. Among people with T2DM, 41.6\% of them did not have a cognitive impairment, $41.6 \%$ had MCI, and 16.8\% had Alzheimer's disease [9]. The prevalence of MCI among people with T2DM at Gunungpati PHC was $70 \%(54 \%-86 \%)$.

The incidence of MCI is higher in individuals with T2DM than those who do not have T2DM. Although the pathophysiology of MCI in T2DM is unclear, many studies show that changes in pathoglycaemia, DM complications, and psychological status are significant risk factors. Previous research indicates that DM correlates with cognitive impairment and neurodegenerative diseases. Prevention on modifying the risk factors might reduce the risk of MCI and dementia [8], [9], [11]-[17].

Several studies of risk factors for MCI among T2DM patients have shown inconsistent results. It might be due to differences in study design, study subjects, diagnostic criteria for T2DM or MCI. However, it might also be due to the duration or severity of T2DM. In this casecontrol study, we investigated the association between duration of T2DM and risk factors of severity (such as age, sex, physical activity, BMI, hypertension, stroke, medication compliance, smoking, and stress) with MCI.

\section{Methods}

We did a case-control study with 68 cases and 68 controls. Case was defined as all subjects with T2DM who participated in this study and were found to be affected by MCI. Control was defined as all subjects with T2DM who participated in this study and were found to be cognitively normal. We assessed MCI among people with T2DM and the risk factors. i.e duration of T2DM, age, sex, physical activity, BMI, hypertension, stroke, medication compliance, smoking, and stress. MCI was assessed using Mini-Mental State Examination (MMSE), whereas the risk factors were assessed using structured questionnaire. We used logistic regression models to know the association between duration of T2DM with MCI after adjusted with other risk factors.

\section{Results and Discussion}

We assessed 136 subjects with T2DM. Based on demographic characteristics and risk factors (Table 1), there were 61 subjects $(44.85 \%)$ with duration of $\mathrm{T} 2 \mathrm{DM} \geq 5$ years and 75 subjects $(55.14 \%)$ with duration of T2DM $<5$ years. It also showed that 104 subjects aged 5060 years $(76.47 \%)$ and 32 subjects aged $40-49$ years $(23.52 \%)$. Then, there were 108 females $(79.41 \%)$ and 28 males $(20.58 \%)$. Subjects with risky physical activity were $73(53.67 \%)$ and non-risky physical activities were $63(46.32 \%)$. Then it is known that subjects with obese BMI were $39(28.67 \%)$ and subjects with normal BMI were 97 (71.32\%). Subjects who hypertension were $80(58.82 \%)$ and subjects who did not have hypertension were $56(41.17 \%)$. Subjects with 
stroke were $14(10.29 \%)$ and 122 subjects without stroke $(89.70 \%)$. Then, there were 68 subjects $(50 \%)$ who complied with taking the medicine and 68 subjects $(50 \%)$ did not comply. Subjects who had smoking habits were $21(15.44 \%)$ and did not have smoking habits were $115(84.55 \%)$. Then, for subjects who had stress were $25(18.38 \%)$ while those who were not stressed were $111(81.61 \%)$

Table 1. Demographic characteristic and risk factors among 136 people with T2DM in Semarang City, Indonesia

\begin{tabular}{|c|c|c|}
\hline $\begin{array}{l}\text { Risk Factors } \\
\end{array}$ & $\mathbf{N}$ & $\%$ \\
\hline \multicolumn{3}{|l|}{ Duration of T2DM } \\
\hline$\geq 5$ years & 61 & 44.85 \\
\hline$<5$ years & 75 & 55.14 \\
\hline \multicolumn{3}{|l|}{ Age } \\
\hline 50-60 years & 104 & 76.47 \\
\hline 40-49 years & 32 & 23.52 \\
\hline \multicolumn{3}{|l|}{ Sex } \\
\hline Female & 108 & 79.41 \\
\hline Male & 28 & 20.58 \\
\hline \multicolumn{3}{|l|}{ Physical activity } \\
\hline$<3$ times a week & 73 & 53.67 \\
\hline$\geq 3$ times a week & 63 & 46.32 \\
\hline \multicolumn{3}{|l|}{$\mathrm{BMI}$} \\
\hline Obesity & 39 & 28.67 \\
\hline Normal & 97 & 71.32 \\
\hline \multicolumn{3}{|l|}{ Hypertension } \\
\hline Yes & 80 & 58.82 \\
\hline No & 56 & 41.17 \\
\hline \multicolumn{3}{|l|}{ Stroke } \\
\hline Yes & 14 & 10.29 \\
\hline No & 122 & 89.70 \\
\hline \multicolumn{3}{|l|}{ Medication compliance } \\
\hline No & 68 & 50.00 \\
\hline Yes & 68 & 50.00 \\
\hline \multicolumn{3}{|l|}{ Smoking } \\
\hline Yes & 21 & 15.44 \\
\hline No & 115 & 84.55 \\
\hline \multicolumn{3}{|l|}{ Stress } \\
\hline Yes & 25 & 18.38 \\
\hline No & 111 & 81.61 \\
\hline
\end{tabular}

The collected data were tested by chi-square test. It showed from Table 2 that some risk factors are associated with MCI ( $\mathrm{p}$ value $<0.05$ ), i.e. duration of T2DM, age, physical activity, hypertension, medication compliance, and stress. Otherwise, sex, BMI, stroke, and smoking were not shown to be significantly associated with MCI. Based on the result from duration of T2DM, the Odds Ratio (OR) was 3.64 (95\% CI: 1.79-7.43), which means that subjects who had duration of $\mathrm{T} 2 \mathrm{DM} \geq 5$ years had a 3.64 times higher risk of getting MCI than those who had duration of T2DM < 5 years. In age variable, OR was 6.39 (95\% CI: 2.42-16.87), which means that subjects aged 50-60 years had a 6.39 times higher risk of getting MCI than those who were 40-49 years. OR of physical activity, hypertension, medication compliance, and stress were 3.17 
(95\% CI: 1.57-6.41), 2.09 (95\% CI: 1.04-4.19), 2.3 (95\% CI: 1.16-4.58), and 3.14 (95\% CI: 1.21-8.11), respectively. The risk of getting MCI among people with less physical activity, hypertension, lack of medication compliance, or stress was almost three times higher than in people with physical activity $\geq 3$ times a week, no-hypertension, medication compliance, and no-stress.

Table 2. Bivariable analysis of risk factors of MCI among 136 people with T2DM in Semarang City, Indonesia

\begin{tabular}{|c|c|c|c|c|}
\hline Risk Factors & $\begin{array}{c}\text { Cases } \\
(\mathrm{n}=68) \\
\mathrm{n}(\%)\end{array}$ & $\begin{array}{c}\text { Controls } \\
(\mathrm{n}=68) \\
\mathrm{n}(\%)\end{array}$ & OR $(95 \% \mathrm{CI})$ & p-value* \\
\hline \multicolumn{5}{|l|}{ Duration of T2DM } \\
\hline$\geq 5$ years & $41(60.3)$ & $20(29.4)$ & $3.64(1.79-7.43)$ & 0.01 \\
\hline$<5$ years & $27(39.7)$ & $48(70.6)$ & & \\
\hline \multicolumn{5}{|l|}{ Age } \\
\hline 50-60 years & $62(91.2)$ & $41(61.8)$ & $6.39(2.42-16.88)$ & 0.01 \\
\hline 40-49 years & $6(8.8)$ & $26(38.2)$ & & \\
\hline \multicolumn{5}{|l|}{ Sex } \\
\hline Female & $52(76.5)$ & $56(82.4)$ & $0.69(0.3-1.61)$ & 0.39 \\
\hline Male & $16(23.5)$ & $12(17.6)$ & & \\
\hline \multicolumn{5}{|l|}{ Physical activity } \\
\hline$<3$ times a week & $46(67.6)$ & $27(39.7)$ & $3.17(1.57-6.41)$ & 0.01 \\
\hline$\geq 3$ times a week & $22(32.4)$ & $41(60.3)$ & & \\
\hline \multicolumn{5}{|l|}{$\mathrm{BMI}$} \\
\hline Obesity & $17(25.0)$ & $22(32.4)$ & $0.69(0.33-1.47)$ & 0.34 \\
\hline Normal & $51(75.0)$ & $46(67.6)$ & & \\
\hline \multicolumn{5}{|l|}{ Hypertension } \\
\hline Yes & $46(67.6)$ & $34(50.0)$ & $2.09(1.04-4.19)$ & 0.04 \\
\hline No & $22(32.4)$ & $34(50.0)$ & & \\
\hline \multicolumn{5}{|l|}{ Stroke } \\
\hline Yes & $8(11.8)$ & $6(8.8)$ & $1.37(0.45-4.2)$ & 0.57 \\
\hline No & $60(88.2)$ & $62(91.2)$ & & \\
\hline \multicolumn{5}{|l|}{ Medication compliance } \\
\hline No & $41(60.3)$ & $27(39.7)$ & $2.3(1.16-4.58)$ & 0.02 \\
\hline Yes & $27(39.7)$ & $41(60.3)$ & & \\
\hline \multicolumn{5}{|l|}{ Smoking } \\
\hline Yes & $12(17.6)$ & $9(13.2)$ & $1.4(0.55-3.59)$ & 0.48 \\
\hline No & $56(82.4)$ & $59(86.8)$ & & \\
\hline \multicolumn{5}{|l|}{ Stress } \\
\hline Yes & $18(26.5)$ & $7(10.3)$ & $3.14(1.21-8.11)$ & 0.01 \\
\hline No & $50(73.5)$ & $61(89.7)$ & & \\
\hline
\end{tabular}

*Chi-square test

The multivariabel analysis was done in the variables of duration of T2DM, age, physical activity, and stress. This model was the best model because all rik factors are significantly associated. It is adjusted for sex, BMI, hypertension, stroke, medication compliance, and smoking. The adjusted ORs were significantly elevated 3-fold for subjects with T2DM with duration of $\mathrm{T} 2 \mathrm{DM} \geq 5$ years. 
Table 3. Multivariable analysis of risk factors of MCI among 136 people with T2DM in Semarang City, Indonesia

\begin{tabular}{lrr}
\hline \multicolumn{1}{c}{ Risk Factors } & AdjOR (95\% CI)* & p-value \\
\hline Duration of T2DM & $3.24(1.42-7.42)$ & 0.01 \\
Age & $6.67(2.15-20.73)$ & 0.01 \\
Physical activity & $3.65(1.61-8.26)$ & 0.01 \\
Stress & $4.37(1.36-14.06)$ & 0.01 \\
\hline
\end{tabular}

*Adjusted for sex, BMI, hypertension, stroke, medication compliance, and smoking

The results showed that there was association between duration of T2DM and MCI. The duration of getting T2DM $\geq 5$ years was associated with greater cerebral macrovascular disease, clinical cerebral infarction, and subclinical infarction that impaired cognitive function. Longer experience of T2DM is associated with chronic hyperglycemia, which increases the likelihood of microvascular disease and can contribute to neuronal damage, brain atrophy, and MCI [8]. Besides the duration of T2DM, the risk factors for age, physical activity, and stress also showed significant association to MCI. It is not only the elderly population who are likely to get MCI. Another study reported that the decline in cognitive function has started to occur in middle age, starting at 45-49 years of age. The risk of developing MCI in middle adulthood may increase if there are metabolic factors [7]. With increasing age, a degenerative process occurs in the brain which is characterized by brain atrophy. Atrophy in the hippocampus results in decreased memory function which causes MCI [18].

The study also indicated that the higher the physical activity, the better the cognitive function. The level of physical activity is positively related to brain volume, white matter volume, and gray matter volume. Physical activity can increase neurogenesis and neurotrophic factor brain derived neurotropic factor (BDNF) which can increase the resistance and growth of several types of neurons, including glutamanergic neurons. Brain derived neurotropic factor (BDNF) acts as a major mediator of synaptic efficacy, nerve cell liaison, and nerve cell plasticity. Significantly, this effect occurs in the hippocampus, the region of the brain where learning and memory are centered. Physical activity can increase brain vascularity and contribute to maintaining cognitive function during aging [17].

MCI is also determined by stress. The cells and tissues that are most susceptible to oxidative stress are brain cells. Oxidative stress can result in damage to glial cells and neurons which can lead to decreased cognitive function [19].

\section{Conclusion}

The study revealed that the duration of T2DM was significantly associated with MCI among people with T2DM. Based on multivariable analysis, we also know that not only duration of T2DM, but also age, physical activity, and stress also showed significant association to MCI.

\section{References}

[1] WHO, "Management of Substance Abuse Unit. Global status report on alcohol and health," 2014.

[2] Kemenkes RI, "Riset Kesehatan Dasar," Jakarta, 2018.

[3] D. K. P. J. Tengah, Profil Kesehatan Provinsi Jawa Tengah Tahun 2018. Semarang: Dinas 
Kesehatan Provinsi Jawa Tengah.

[4] Kemenkes RI, "Situasi dan Analisis Diabetes." 2014.

[5] Kemenkes RI, "Gambaran Kesehatan Lanjut Usia di Indonesia," 2013.

[6] S. Yang, Z. Xu, Y. Xiong, Y. Zhan, L. Guo, and S. Zhang, "Altered Intranetwork and Internetwork Functional Connectivity in Type 2 Diabetes Mellitus With and Without Cognitive Impairment," Nat. Publ. Gr., no. September, pp. 1-11, 2016, doi: 10.1038/srep32980.

[7] A. C. J. Nooyens, C. A. Baan, A. M. W. Spijkerman, and W. M. Monique Verschuren, "Type 2 diabetes and cognitive decline in middle-aged men and women: The doetinchem cohort study," Diabetes Care, vol. 33, no. 9, pp. 1964-1969, 2010, doi: 10.2337/dc092038.

[8] Y. Gao, Y. Xiao, R. Miao, J. Zhao, and M. Cui, "The prevalence of mild cognitive impairment with type 2 diabetes mellitus among elderly people in China : A cross-sectional study," Arch. Gerontol. Geriatr., 2015, doi: 10.1016/j.archger.2015.09.003.

[9] W. Li, T. Wang, and S. Xiao, "Type 2 diabetes mellitus might be a risk factor for mild cognitive impairment progressing to Alzheimer' s disease," Neuropsychiatr. Dis. Treat., vol. 12, pp. 2489-2495, 2016.

[10] R. C. Petersen et al., "Mild Cognitive Impairment: Ten Years Later," vol. 66, no. 12, pp. 1447-1455, 2011, doi: 10.1001/archneurol.2009.266.Mild.

[11] R. O. Roberts et al., "Association of duration and severity of diabetes mellitus with mild cognitive impairment," Arch. Neurol., vol. 65, no. 8, pp. 1066-1073, Aug. 2008, doi: 10.1001/archneur.65.8.1066.

[12] X. Yuan and X. Wang, "Mild cognitive impairment in type 2 diabetes mellitus and related risk factors : a review," de gruyter, pp. 1-9, 2017, doi: 10.1515/revneuro-2017-0016.

[13] O. Albai, M. Frandes, R. Timar, D. Roman, and B. Timar, "Risk factors for developing dementia in type 2 diabetes mellitus patients with mild cognitive impairment," Neuropsychiatr. Dis. Treat., vol. 15, pp. 167-175, 2019.

[14] Y. Cukierman, "Relationship Between Baseline Glycemic Control and Cognitive Function in Individual With Type 2 Diabetes and Other Cardiovascular Risk Factors. The Action to Control Cardiovascular Risk in Diabetes-Memory in Diabetes (ACCORD-MIND) trial," Diabetes Care, vol. 32, no. 2, pp. 221-226, 2009.

[15] C. Degen, P. Toro, P. Schönknecht, C. Sattler, and J. Schröder, "Diabetes Mellitus Type II and cognitive capacity in healthy aging, mild cognitive impairment and Alzheimer's disease," Psychiatry Res., 2016, doi: 10.1016/j.psychres.2016.04.009.

[16] J. H. Wu, M. N. Haan, J. Liang, D. Ghosh, H. M. Gonzalez, and W. H. Herman, "Impact of antidiabetic medications on physical and cognitive functioning of older Mexican Americans with diabetes mellitus: A population-based cohort study," Ann. Epidemiol., vol. 13, no. 5, pp. 369-376, 2003, doi: 10.1016/S1047-2797(02)00464-7.

[17] C. W. Cotman and N. C. Berchtold, "Exercise: A behavioral intervention to enhance brain health and plasticity," Trends Neurosci., vol. 25, no. 6, pp. 295-301, 2002, doi: 10.1016/S0166-2236(02)02143-4.

[18] K. Abadi et al., "Hipertensi dan Risiko Mild Cognitive Impairment pada Pasien Usia Lanjut Hypertension and Risk of Mild Cognitive Impairment in Elderly Patients," $J$. Kesehat. Masy. Nas., vol. 8, no. 3, pp. 119-124, 2012.

[19] B. S. O. Diniz, M. S. Yassuda, P. V. Nunes, M. Radanovic, and O. V. Forlenza, "Mini-mental State Examination performance in mild cognitive impairment subtypes," Int. Psychogeriatrics, vol. 19, no. 4, pp. 647-656, 2007, doi: 10.1017/S104161020700542X. 